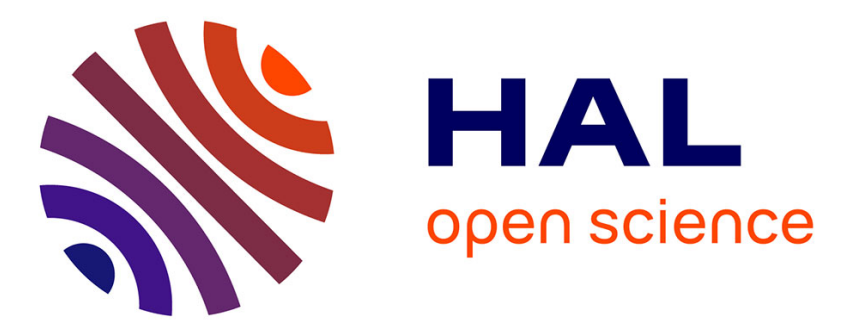

\title{
A subsurface Indian Ocean dipole response to tropical volcanic eruptions
}

Takeshi Izumo, Myriam Khodri, Matthieu Lengaigne, Iyyappan Suresh

\section{To cite this version:}

Takeshi Izumo, Myriam Khodri, Matthieu Lengaigne, Iyyappan Suresh. A subsurface Indian Ocean dipole response to tropical volcanic eruptions. Geophysical Research Letters, 2018, 45 (17), pp.91509159. 10.1029/2018GL078515 . hal-01905855

\section{HAL Id: hal-01905855 https://hal.sorbonne-universite.fr/hal-01905855}

Submitted on 26 Oct 2018

HAL is a multi-disciplinary open access archive for the deposit and dissemination of scientific research documents, whether they are published or not. The documents may come from teaching and research institutions in France or abroad, or from public or private research centers.
L'archive ouverte pluridisciplinaire HAL, est destinée au dépôt et à la diffusion de documents scientifiques de niveau recherche, publiés ou non, émanant des établissements d'enseignement et de recherche français ou étrangers, des laboratoires publics ou privés. 


\section{A subsurface Indian Ocean Dipole response to tropical volcanic}

\section{eruptions} (1) (1) (1)

\section{Corresponding author:}

T. Izumo, takeshi.izumo@ird.fr

\section{Key Points:}

- Tropical volcanic eruptions induce a subsurface ocean response typical of a negative Indian Ocean Dipole (IOD).

- The subsurface response results from equatorial westerlies driven by the large land cooling over Africa.

- The surface signature differs from that of an IOD, with a cooling larger in the northwest than southeast Indian Ocean as a result of the climatological cloud cover distribution.

Keywords: Tropical volcanic eruption, Indian Ocean, Indian Ocean Dipole (IOD), ocean Primary Productivity (PP), Coupled Model Intercomparison Project (CMIP).

${ }^{2}$ Indo-French Cell for Water Sciences, IISc-NIO-IITM-IRD Joint International Laboratory, NIO, Goa, India ${ }^{3}$ CSIR-National Institute of Oceanography, Goa, India

Submitted to Geophysical Research Letters, April 2018, revised on July 4th, 2018. 
Abstract. The impacts of explosive volcanism on the densely-populated Indian Ocean (IO) region remain elusive. Dedicated sensitivity experiments indicate that 31 tropical volcanic eruptions induce a stronger surface cooling over Africa than of ocean, 32 promoting westerlies in the equatorial IO. These westerlies drive a subsurface response 33 reminiscent to that of a negative IO Dipole (IOD) during autumn in the year of eruption. 34 The eruption also drives an enhanced cooling over the northwestern IO as a direct 35 response to climatological cloud cover distribution. The resulting anomalous zonal sea surface temperature gradient contributes to enhance equatorial westerly anomalies in summer. The response is sensitive to the IO preconditioning, being larger when the system is favourable to a positive IOD development. Volcanic eruptions also induce a subsurface IOD-like response in the multi-model database from the Coupled Model Intercomparison Project Phase 5 as well as a primary productivity decrease in the eastern IO.

42

Plain text summary. Explosive volcanism induces a global surface cooling but its 44 regional impact on the densely-populated Indian Ocean sector is poorly documented. Here we show that the volcanic eruptions induce a subsurface ocean response in autumn of the eruption's year, reminiscent to that of a negative Indian Ocean Dipole, an intrinsic climate mode in the Indian Ocean equivalent to El Niño in the Pacific. This subsurface response is driven by equatorial westerly anomalies resulting from the stronger surface cooling over the African landmass than over the ocean. The response is sensitive to the Indian Ocean preconditioning, being larger when the system is preconditioned towards a positive Indian Ocean Dipole development. 
The densely populated region surrounding the Indian Ocean (IO) is socioeconomically very sensitive to climate variability. As Sea Surface Temperatures (SSTs) in the IO often exceeds the $28^{\circ} \mathrm{C}$ threshold for deep atmospheric convection (e.g. Graham and Barnett, 1987), small SST perturbations can force a significant atmospheric response. This sensitivity promotes active air-sea interactions, which give rise to the Indian Ocean Dipole (IOD; Reverdin et al. 1986, Saji et al. 1999, Webster et al. 1999, Murtugudde et al. 2000), an intrinsic mode of climate variability in the IO equivalent of El Niño/La Niña Southern Oscillation (ENSO) in the Pacific. A negative IOD (nIOD) is characterized by a surface warming and an anomalously deep thermocline off the west coasts of Java and Sumatra and by a cooling and anomalously shallow thermocline anomalies in the west IO, driven by anomalous westerlies over the central equatorial IO. A positive IOD (pIOD) is characterized by opposite anomalies. IOD events usually develop in boreal summer and peak in autumn. El Niño and La Niña events respectively favour positive and negative IODs, but IOD can also occur independently of ENSO (e.g. Annamalai et al. 2003; Yamagata et al. 2004). The IOD has important implications at regional scale on the IO climate and monsoon (e.g. Schott et al. 2009), tropical cyclones (Xie et al. 2002), oceanic primary production (Curie et al. 2013) and oxygen (Vallivattathillam et al. 2017), and also at global scale by influencing the Madden-Julian Oscillation (e.g. Izumo et al. 2010b) and ENSO (e.g. Izumo et al. 2010a, 2014, 2016, Jourdain et al. 2016).

Stratospheric tropical volcanic eruptions induce a temporary global radiative cooling that directly impacts the earth climate by inducing a surface cooling at the global scale (see Robock, 2000 for a review). This cooling is larger on land than on ocean, resulting in an overall rainfall reduction over the tropical landmass (e.g. Schneider et al. 2009, Joseph and Zeng 2011, Iles and Hegerl 2014). The upper ocean cooling translates into an Oceanic Heat Content (OHC) decrease (e.g. Church et al. 2005, Gleckler et al. 2006, Stenchikov et al. 2009, Mignot et al. 2011). The climatological cloud cover and oceanic mixed layer depth (MLD) distributions however induce a spatially inhomogeneous ocean cooling: e.g. a clear sky and thin MLD induces a larger cooling (McGregor and Timmerman 2011, Ohba et al. 2013). Such land/sea thermal contrast and inhomogeneous ocean cooling also results in specific regional climate 
responses. Notably, Khodri et al. (2017, hereafter K17) demonstrated using dedicated sensitivity experiments that the larger cooling over tropical Africa than over the ocean force westerlies over the western Pacific, hence favouring an El Niño the year following the eruption.

While the Pacific response to tropical volcanic eruptions has been extensively documented (see K17 and the references therein), there is to date no study focusing on the detailed response of the IO to these eruptions. The present study aims to fill this gap by analysing the Pinatubo-forced sensitivity experiments designed in K17 as well as simulations from the Coupled Model Intercomparison Project phase 5 (CMIP5; Taylor et al. 2012).

\section{2) Models, experimental strategy and methods}

\subsection{The IPSL-CM5B LR model and the experimental strategy}

In this study, we use the same set of simulations as in K17 performed with the IPSLCM5B-LR climate model (cf. Supplementary Information - hereafter SI, its section 2, for details on the modelling setup). This model couples the LMDZ5B (Hourdin et al. 2013) atmospheric and NEM03.2 (Madec 2015) oceanic components, and accurately captures the main observed IOD characteristics (Jourdain et al. 2016).

We focus on the Pinatubo eruption (June 15 ${ }^{\text {th }}, 1991$ ), as it is the strongest and bestobserved tropical stratospheric eruption during the instrumental period. The main set of coupled (CPL hereafter) simulations consists of a pair of 3-year-long ensemble experiments of 30 members each with (PTUBO) and without (CTL) a Pinatubo-like forcing. These simulations are initialized on June $1^{\text {st }}$ of a selected year from the historical simulation (with neutral El Nino Southern Oscillation (ENSO) conditions in the absence of volcanic forcing, avoiding any interference with external ENSO forcing).

The CPL response to volcanic forcing is assessed by performing the difference between PTUBO and CTL experiments (CPL = PTUBO-CTL), internal climate variability being reduced by the ensemble average. Significance and confidence intervals are computed from usual two-tailed Student t-tests, each member being an independent degree of freedom.

We also analyse the following dedicated atmospheric experiments performed with the atmospheric component of the IPSL-CM5B model (K17). They are forced by the 
118 coupled model outputs to assess the dominant mechanisms driving the I0 response:

119 (1) ATM experiments assess the direct effect of volcanic radiative forcing on clouds 120 and atmospheric vapour content (Soden et al. 2002).

121 (2) OCEAN experiments assess the indirect effects of volcanic forcing on the 122 atmospheric response through the SST inhomogeneous cooling.

123 (3) LAND experiments quantify the effect of the stronger cooling over land than 124 over the ocean. An additional sensitivity experiment finally isolates the specific role of 125 the cooling over African landmass (LAND-Africa).

126 Finally, the relevance of the two-tier approach is assessed using an experiment 127 including all these three processes (ALL).

\subsection{Linear Continuously Stratified (LCS) and slab ocean models}

129 The equatorial IO dynamical response to windstress anomalies resulting from each 130 sensitivity experiment is then estimated by forcing a Linear Continuously Stratified 131 (LCS; McCreary, 1980) ocean model of the Indo-Pacific region (Izumo et al. 2016, 2018 132 configuration; cf. SI). This LCS realistically simulates sea surface height (SSH) variations 133 in the Indo-Pacific region (Suresh et al. 2013, 2016; Izumo et al. 2016, 2018), despite 134 being linear and simple.

135 A simple slab ocean mixed layer equation using a spatially-varying monthly 136 climatological mixed layer depth is also used, to simulate the SST thermodynamical 137 response to the eruption-induced Short-Wave (SW) flux anomalies (see SI), following 138 the approach of McGregor and Timmerman (2011). 


\subsection{CMIP5 simulations}

140 The robustness of the response from our single model experiments is further 141 assessed by analysing historical simulations from the CMIP5 multi-model dataset over 142 the 1861-2005 period (Suppl. Table S1). As reported in many previous studies (e.g. 143 Jourdain et al. 2016), CMIP5 simulations, in general, accurately capture the IOD 144 seasonality and pattern but overestimate its amplitude. Their response to tropical volcanism is estimated here by compositing the 5 largest historical tropical eruptions, 146 keeping in mind that these eruptions exhibit different amplitudes and seasonal 147 evolutions (cf. Fig. S1).

148 We use the classical Dipole Mode Index (DMI, the SST difference between $50-70^{\circ}$ E, $10^{\circ} \mathrm{N}-10^{\circ} \mathrm{S}$ west and $90-110^{\circ} \mathrm{E}, 0-10^{\circ} \mathrm{S}$ east poles; Saji et al. 1999) to identify IOD events, as well as the SSH averaged over the DMI eastern pole box, the SSH being an accurate proxy for OHC and thermocline depth variations (Rebert et al. 1985).

Figure 1ac displays the surface and ocean subsurface ensemble mean CPL response to the Pinatubo eruption. As expected, there is an overall cooling over the IO region, stronger over land than at the ocean surface. The SST cooling is larger over the northwest than over the southeast IO, leading to a northwest-southeast anomalous SST gradient (Fig. 1a), which translates into a dipolar pattern in terms of relative SST (i.e. 160 SST minus its $20^{\circ} \mathrm{N}-20^{\circ} \mathrm{S}$ tropical mean; cf. SI, K17; Held and Soden 2006; Vecchi and 161 Soden 2007) and precipitation (Fig. S2). The equatorial IO is also characterized by 162 significant westerly/north-westerly anomalies, larger in the eastern IO. The SSH and 163 related subsurface oceanic response (Fig. 1c) is typical of a negative IOD (cf. Fig. S3; 164 Murtugudde et al. 2000, Currie et al. 2013), with a downwelling signal along the coast of Java and Sumatra and the Bay of Bengal rim and an upwelling signal in the central and western IO maximum off the equator.

The LCS experiment forced by CPL ensemble wind stress (Fig. 1d) accurately 168 captures the major SSH signature simulated by the coupled model (Fig. 1c), demonstrating that linear ocean dynamics explains most of the coupled model response.

170 There is however a positive SSH offset over the entire IO, because the LCS physics 171 cannot simulate in essence the SSH decrease related to the overall upper ocean cooling 
172 driven by volcanically-induced surface heat flux anomalies (e.g. Church et al. 2005, 173 Gleckler et al. 2006, Stenchikov et al. 2009). The volcanically-induced wind stress 174 anomalies easily explain the SSH dipolar pattern: equatorial westerlies indeed induce 175 downwelling equatorial Kelvin waves deepening the thermocline in the eastern IO and 176 westward propagating equatorial Rossby waves shallowing the thermocline in the 177 central and western IO.

178 As the IO subsurface response to volcanic forcing is qualitatively similar to that of a negative IOD (hereafter nIOD) but different at the surface, we will term this response as a « volcanic subsurface nIOD». This ensemble mean response is about one-third to a half of the typical SSH amplitudes during a typical IOD simulated by the IPSL model (Fig. S3).

182 It is significant at the $99 \%$ level for the DMI east pole SSH. The SST pattern is different 183 from that of a typical IOD (Fig. S3), although it projects onto DMI poles (Figs 1a and S2a), leading to a significant negative DMI anomaly of $-0.4^{\circ} \mathrm{C}$.

The subsurface ocean response is largely wind driven (Fig. 1cd). We hence analyse the dedicated sensitivity atmospheric experiments described in Section 2 to understand the mechanisms responsible for the anomalous equatorial westerlies. The similar wind patterns depicted in CPL and ALL experiments confirm the relevance of this two-tier approach (Fig. 1ab). Despite a 30\% overestimation of the CPL response at its peak, the temporal evolution of equatorial zonal wind-stress (Fig. 2a) and SSH (Fig. 2c) anomalies in ALL experiment are also not statistically distinguishable as a result of the large intermembers spread. LAND process explains most of the equatorial westerly anomalies and related east IO downwelling (Fig. 2b,d). OCEAN process also modestly contributes to these westerly and eastern IO downwelling anomalies at the end of the summer. Finally, ATM influence is negligible, and will not be further discussed. Figure $2 \mathrm{e}$ shows the corresponding surface temperature and wind-stress patterns in autumn for the LAND experiment. As expected from Figure 2b, LAND experiment exhibits equatorial westerlies similar to those in ALL and PTUBO CPL experiments in the equatorial region

199 (Fig. 1). LAND also displays additional strong northeasterly winds in the Arabian Sea, consistent with the expected thermal wind response to the Arabic peninsula cooling (e.g. Samson et al. 2016).

Applying the LAND cooling only over tropical Africa (LAND-Africa) results in a similar equatorial zonal wind (Fig. 2b,f) and SSH (Fig. 2d) evolution as those depicted for LAND, implying that these equatorial westerlies are mainly driven by the African land 
cooling (K17). These westerly anomalies are however shifted northward in this LANDAfrica experiment, most likely because of the absence of the Asian land cooling and 207 related winter monsoon-like circulation anomalies in the eastern Arabian Sea and Bay of 208 Bengal. The African cooling reduces the rainfall and related diabatic heating locally, 209 thereby inducing a Matsuno-Gill response (Gill 1980) with an equatorial atmospheric 210 Kelvin wave forcing to the east of the heating anomaly, consistent with K17 finding. 211 Milder - but significant - westerly anomalies developing in the central east equatorial IO 212 in July-August in OCEAN experiment (Fig. 2b) are arguably a direct response to the 213 northwest-southeast SST gradient seen in Figs 1a and S2. To summarize, Africa-IO land214 sea contrast explains the westerlies and related subsurface nIOD pattern around its 215 peak, but anomalous zonal SST gradients also play a significant role at the early stage of 216 this nIOD.

217 To identify the main driver of the northwest-southeast SST gradient, we performed 218 slab ocean sensitivity experiments forced by the PTUBO minus CTL SW anomalies. They 219 indicate that the inhomogeneous SST cooling largely arises from the climatological cloud 220 cover distribution: the larger climatological cloud cover in the eastern equatorial IO 221 indeed acts to reduce the volcanic SW anomaly at the surface, resulting in a reduced 222 volcano-induced cooling compared to the north-western IO (Fig. S4). The resulting 223 anomalous spatial SST pattern matches qualitatively well with the climatological cloud 224 cover effect

225 We then investigate the sensitivity of the CPL response to the IO preconditioning, 226 defined as the IOD condition that would happen in autumn in the absence of the 227 Pinatubo eruption (i.e. in the CTL simulation). Such sensitivity has already been 228 discussed for ENSO (Ohba et al. 2013; Pausata et al. 2016; K17), but not for the IOD. The 229 dependence of the IO response to the Indo-Pacific initial preconditioning is assessed by analysing two other pairs of 30-members ensemble experiments with and without a 231 Pinatubo-like forcing characterized respectively by El Niño and La Niña conditions in the 232 Pacific during the eruption's year (see SI; K17). We gather the three CTL 30-members 233 ensembles into a large 90-members ensemble, and then classify them depending on 234 their IOD conditions in autumn of the eruption's year, gathering members showing a 235 DMI above $0.5^{\circ} \mathrm{C}\left(21\right.$ members), below $-0.5^{\circ} \mathrm{C}$ ( 49 members), and between $-0.5^{\circ} \mathrm{C}$ and $0.5^{\circ} \mathrm{C}$ (20 members). Classifying members based on ENSO conditions in the Pacific gives 237 qualitatively similar results (with slightly less differenciation), because of the tendency 
of ENSO and IOD events to co-occur.

Figure 3 displays the evolution of the DMI (Fig. 3a-c) and eastern SSH (Fig. 3d-f) 240 anomalies in CTL and PTUBO experiments for these three classes (even if the SST 241 response is different from that of an IOD, the DMI is used here to describe the SST 242 asymmetries as it broadly captures the spatial anomalies associated with this SST 243 cooling; Fig. S5 and S6). In the absence of an IOD in CTL experiment, volcanic eruptions 244 favour a nIOD-like response both at depth $(\sim 2 \mathrm{~cm} \mathrm{SSH}$ anomaly in the eastern IO; Fig. $2453 \mathrm{~d})$ and at the surface $\left(-0.4^{\circ} \mathrm{C}\right.$ DMI anomaly; Fig. 3a). In the presence of a positive IOD in 246 CTL, volcanic eruptions induce a similar subsurface response $(\sim 2 \mathrm{~cm}$; Fig. $3 \mathrm{de})$ but a 247 larger SST response $\left(-0.7^{\circ} \mathrm{C}\right.$; Fig. $\left.3 \mathrm{ab}\right)$, which acts to considerably reduce the positive 248 IOD amplitude. In the presence of a negative IOD in CTL, volcanic eruptions induce a weaker subsurface response $(\sim 1.2 \mathrm{~cm}$; Fig. 3f $)$ and no significant SST gradient change (Fig. 3c). The asymmetry to IO background conditions is hence larger for the SST gradient than for the subsurface response. The asymmetry of the SST response mainly arises from the IOD eastern pole (Fig. S5c), and could be explained by two processes 253 described below in the case of a negative IOD background condition. First, because of 254 the non-linearity of the Clausius-Clapeyron equation, the evaporation negative feedback damps more the volcanically-induced relative warming in the eastern pole during a negative IOD as SSTs are warmer in the eastern IO. Second, the deep background thermocline in the eastern IO during a negative IOD makes the positive thermocline depth anomalies forced by the eruption westerlies less efficient to warm the eastern IO SST. While the asymmetry in the subsurface response is weaker, the presence of a negative IOD in CTL experiment makes the subsurface response $\sim 1.5$-2 times weaker, shorter, and occuring later (only significant at the $90 \%$ level in Nov.-Dec.; not shown).

262 This suggests that the volcanically-induced SST gradient could contribute, by forcing additional westerlies, to the subsurface IOD, and to its asymmetry. However, our modelling setup can not precisely quantify this contribution from the ocean-atmosphere coupling.

The robustness of the IO response to volcanic forcing derived from our single model analysis is finally assessed by analysing the multi-model CMIP5 database. Composites of the five historical tropical eruptions in autumn of the eruption's year in the CMIP5 multi-model ensemble mean (48 models/158 members, cf. SI) show patterns of surface temperature, relative SST, wind stress (Fig. 4a) and sea level (Fig. 4b) that share a lot in 
271 common with those obtained for our ensemble strategy using the IPSL-CM5B model for

272 the Pinatubo eruption (Fig. 1ac). This includes a larger cooling over land than over the

273 ocean, a larger SST cooling over the northwest IO, an equatorial westerly anomaly and a

274 significant subsurface oceanic response typical of a nIOD.

275 This overall consensus between our simulations and CMIP5 multi-model database

276 suggests that the results discussed in this paper are relevant for most climate models

277 used in the CMIP5 exercise. There are however significant differences between our

278 single model experiments and the CMIP5 MME multi-eruption response, generally

279 weaker (e.g. nIOD subsurface signal of only 20\% of that of a typical IOD in CMIP5 MME,

280 instead of $\sim 30-50 \%$ in CPL). This amplitude however considerably varies among models

281 (not shown). This weaker response in the MME likely partly arises from our set-up, 282 specifically designed for the Pinatubo eruption (Fig. S1). The spread of the inter-model 283 response could also be related to the different models physics and to internal variability 284 (and random preconditioning) of each historical run.

4) Discussion

Analyses of dedicated coupled experiments with the IPSL-CM5B model forced by a Pinatubo-like eruption and CMIP5 models historical runs demonstrate that tropical volcanic eruptions force a subsurface response typical of nIOD. The surface response exhibits an enhanced cooling over the northwestern IO, resulting in a northwest/southeast sea surface temperature gradient. Although this inhomogeneous SST pattern projects onto the classical DMI, it differs from the classical IOD SST pattern. We thus term this response a « volcanic subsurface nIOD ». A hierarchy of models shows that this nIOD-like subsurface signature is caused by equatorial westerly anomalies, that are themselves largely an atmospheric Kelvin wave response to the fast land cooling over tropical Africa. These westerlies seem to be also enhanced by the heterogeneous ocean surface cooling, attributable to the heterogeneous climatological cloud cover. Finally we show that the SST and subsurface responses depend on the IO preconditioning, with a larger response when the system is favourable to a positive IOD development, especially for the SST. 
still modest, $30-50 \%$ of a typical IOD in IPSL CM5B. For neutral background conditions,

304 the amplitude of the DMI SST response reaches $\sim 0.4^{\circ} \mathrm{C}$, a value comparable to the ENSO 305 response in the same model $\left(0.5^{\circ} \mathrm{C}\right.$ Niño3.4 relative SST anomalies; K17). Given that the 306 Pinatubo eruption is relatively modest compared to other eruptions over longer 307 geological timescales, we expect the volcanic nIOD to be much stronger for very strong 308 eruptions, e.g. during the last millennium. Volcanic nIOD amplitude also considerably varies among CMIP models, and will certainly depend on the model, the volcanic forcing, and the eruption characteristics (strength, season, duration, latitude; Stevenson et al. 2016). The OCEAN process depends likely also on the volcanically-induced El Niño response, which could interfere destructively with the IO local SST response by forcing 313 IO easterlies. Alleviating the dry bias in the eastern IO present in the current CMIP 314 models (e.g. Li et al. 2015) could also increase the SST gradient response by increasing the climatological cloud cover effect (cf. Fig. S4), and therefore the OCEAN effect. All these questions highlight the need of similar experiments in other models, as proposed in the coming CMIP6 VolMIP exercise (Zanchettin et al. 2016).

Here we have demonstrated that a negative subsurface IOD develops in autumn of the eruption's year. Maher et al. (2016) has interestingly briefly mentioned the tendency for a positive IOD-like SSH pattern to develop in autumn of the eruption's following year in CMIP models and attributed this to an indirect response to the concurrent El Niño signal peaking in the Pacific. Indeed, CMIP5 MME IOD temporal evolution indicates both the direct negative IOD response in the eruption's year and the indirect positive IOD the following year (Fig. S6). Removing ENSO influence through linear regression confirms that the positive IOD occurring the year after the eruption is mainly an indirect response to the co-occurring El Niño in the Pacific, while the negative IOD response during the year of the eruption is not. The direct response in CMIP MME $(+0.8 \mathrm{~cm} \mathrm{SSH}$ in SON of eruption's year for eastern DMI pole) is of the same order of magnitude as the El Niñoinduced positive IOD in following year's SON (-1.2 cm; not shown).

The « volcanic subsurface negative IOD » does not exhibit a typical IOD signature at the surface, resulting in different climate impacts. The rainfall pattern (and thus atmospheric teleconnections) is indeed different (Figs S2b and S7b) from a typical IOD 333 (Fig. S3): e.g. the strong land cooling over the maritime continent favours a drying, while 334 the negative IOD-like relative SST warming (Figs 1a, S2a and S7a) favours rainfall over the east IO. 
In contrast, subsurface impacts are similar to that of a typical nIOD. Primary production (PP) response in the CMIP5 models (Fig. 4c) is a mirror of SSH, notably in the east IO, Bay of Bengal and Arabian Sea. This PP response fits qualitatively well with the PP patterns expected from a typical IOD (e.g. Murtugudde et al. 1999, Levy et al. 2007, Curie et al. 2013): a 20\% PP decrease along Sumatra (with 16 out of 18 models agreeing on the sign) and a more widespread but weaker PP increase in the west IO, notably along India west coast (with likely a reduction in coastal anoxia and modulation of the oxygen minimum zone; Vallivattathillam et al. 2017). Concerning the IO OHC, IO equatorial westerlies/negative IOD tend to discharge the tropical IO, as shown by idealised switched-on westerlies LCS experiments as in Izumo et al. (2018) study (not shown). El Niño also favours an IO OHC discharge via the Indonesian throughflow (Sprintall and Revelard 2014; Lee et al. 2015). Hence, a tropical eruption, by favouring this nIOD the eruption's year, as well as a following El Niño (Fig. S8; K17), forces a significant IO OHC discharge starting in the eruption's year, the negative OHC anomaly lasting then for several years in the IPSL model (not shown).

Understanding the sensitivity of this volcanic nIOD response to the amplitude, latitude and seasonality of the eruption is the next step forward for improving posteruption climate forecasts.

Acknowledgedments: we would like to thank Dr. Jérôme Vialard, for all the interesting discussions/interactions, and Dr. Christophe Cassou for launching the MORDICUS project, as well as the two anonymous reviewers for their helpful comments. TI, MK and ML are funded by the Institut of Research for Development (IRD). TI and ML gratefully acknowledge the CSIR-NIO for hosting them during their stays there, under IRD funding, and would like to thank their colleagues at NIO for their hospitality and help. Part of this work has been funded by the French Agence Nationale de la Recherche (Grant no. ANR-10-LABX-18-01, Grant no. ANR-13-SENV-0002-02). IPSL and LCS data plotted here are available as Supplemental netcdf datasets. We acknowledge the World Climate Research Program's Working Group on Coupled Modelling, which is responsible for CMIP, and we thank the climate modeling groups (listed in Table S1) for producing and making available their model outputs. All the CMIP5 model outputs were downloaded from the Institut Pierre Simon Laplace (IPSL) CICLAD repository. A more detailed discussion can be found in the supporting information [Sobel et al. 2001 ; Saji et al. 2006; Joshi et al. 2008 ; Gao et al. 2008]. 
Annamalai H., R. Murtugudde, J. Potemra, S. P. Xie, P. Liu, and B. Wang, 2003: Coupled dynamics in the Indian Ocean: Spring initiation of the zonal mode. Deep-Sea Res. II, 50, 2305-2330.

Chikamoto, M. O., A. Timmermann, M. Yoshimori, F. Lehner, A. Laurian, A. Abe-Ouchi, A. Mouchet, F. Joos, C. C. Raible, and K. M. Cobb (2016), Intensification of tropical Pacific biological productivity due to volcanic eruptions, Geophys. Res. Lett., 43, doi:10.1002/2015GL067359.

Church, J. A., White, N. J., and Arblaster, J. M. (2005). Significant decadal-scale impact of volcanic eruptions on sea level and ocean heat content. Nature, 438(7064), 74.

Compo, G. P. and Sadershmukh, P. D. Oceanic influences on recent continental 333-342 (2009).

Currie, J. C., Lengaigne, M., Vialard, J., Kaplan, D. M., Aumont, O., Naqvi, S. W. A., and Maury, O. (2013). Indian Ocean Dipole and El Nino/Southern Oscillation impacts on regional chlorophyll anomalies in the Indian Ocean. Biogeosciences, 10(10), 6677.

Dommenget, D. The ocean's role in continental climate variability and change. J. Climate 22, 4939-4952 (2009).

Gadgil, S., Vinayachandran, P. N., and Francis, P. A. (2003). Droughts of the Indian summer monsoon: Role of clouds over the Indian Ocean. Current Science, 1713-1719.

Gao, C., Robock, A. and Ammann, C, 2008. Volcanic forcing of climate over the past 1500 years: An improved ice core-based index for climate models. J. Geophys. Res. 113, D23111.

Gill, A. E. Some simple solutions for heat-induced tropical circulation. Q. J. R. Meteorol. Soc. 106, 447-462 (1980)

Gleckler, P. J., AchutaRao, K., Gregory, J. M., Santer, B. D., Taylor, K. E., and Wigley, T. M. L. (2006). Krakatoa lives: The effect of volcanic eruptions on ocean heat content and thermal expansion. Geophysical Research Letters, 33(17).

Graham, N. E., and Barnett, T. P. (1987). Sea surface temperature, surface wind divergence, and convection over tropical oceans. Science, 238(4827), 657-659.

Held, I. M., and Soden, B. J. (2006). Robust responses of the hydrological cycle to global warming. Journal of climate, 19(21), 5686-5699.

Hourdin, F., Grandpeix, J. Y., Rio, C., Bony, S., Jam, A., Cheruy, F., ... and Dufresne, J. L. (2013). LMDZ5B: the atmospheric component of the IPSL climate model with revisited parameterizations for clouds and convection. Climate Dynamics, 40(9-10), 2193-2222.

Iles, C. E. and Hegerl, G. C. The global precipitation response to volcanic eruptions in the CMIP5 models. Environ. Res. Lett. 9, 104012 (2014).

Izumo T, Vialard J, Lengaigne M, de Boyer Montegut C, Behera SK, Luo J-J, Cravatte S, Masson S, Yamagata T (2010a) Influence of the Indian Ocean Dipole on following year's El Nino. Nat Geosci 3:168-172 Izumo T, Masson S, Vialard J, de Boyer Montegut C, Behera SK, Madec G, Takahashi K, Yamagata T (2010b) Low and high frequency Madden-Julian Oscillations in Austral Summer - interannual variations. Clim Dyn 35:669-683 Pacific recharge on following year's El Niño: interdecadal robustness. Clim Dyn 42(1-2):291-310 
response from windstress to untangle Indian Ocean Dipole and Basin influences on El Niño. Clim.

Dyn. 46, 2247-2268 (2016).

Izumo, T., Lengaigne, M., Vialard, J., Suresh, I., and Planton, Y. (2018). On the physical interpretation of the lead relation between Warm Water Volume and the El Niño Southern Oscillation. Climate Dynamics, $1-20$.

Joshi, M. M., Gregory, J. M., Webb, M. J., Sexton, D. M., and Johns, T. C. (2008). Mechanisms for the land/sea warming contrast exhibited by simulations of climate change. Climate Dynamics, 30(5), 455-465.

Jourdain, N. C., Lengaigne, M., Vialard, J., Izumo, T., and Gupta, A. S. (2016). Further insights on the influence of the Indian Ocean dipole on the following year's ENSO from observations and CMIP5 models. Journal of Climate, 29(2), 637-658.

Joseph R and Zeng N. Seasonally modulated tropical drought induced by volcanic aerosol J. Clim. 24 2045-60 (2011)

Khodri, M., Izumo, T., Vialard, J., Janicot, S., Cassou, C., Lengaigne, M., ... and Robock, A. (2017). Tropical explosive volcanic eruptions can trigger El Niño by cooling tropical Africa. Nature Communications, 8(1), 778.

Lee, S. K., Park, W., Baringer, M. O., Gordon, A. L., Huber, B., and Liu, Y. (2015). Pacific origin of the abrupt increase in Indian Ocean heat content during the warming hiatus. Nature Geoscience, 8(6), 445.

Lehner, F., A. P. Schurer, G. C. Hegerl, C. Deser, and T. L. Frölicher (2016), The importance of ENSO phase during volcanic eruptions for detection and attribution, Geophys. Res. Lett., 43, doi:10.1002/2016GL067935.

Lévy, M., Shankar, D., André, J. M., Shenoi, S. S. C., Durand, F., and de Boyer Montégut, C. (2007). Basin-wide seasonal evolution of the Indian Ocean's phytoplankton blooms. Journal of Geophysical Research: Oceans, 112(C12).

Li, G., Xie, S. P., and Du, Y. (2015). Monsoon-induced biases of climate models over the tropical Indian Ocean. Journal of Climate, 28(8), 3058-3072.

Madec, G. (2015). NEMO ocean engine. IPSL edition.

Maher, N., S. McGregor, M. H. England, and A. Sen Gupta. Effects of volcanism on tropical variability, Geophys. Res. Lett., 42, 6024-6033, doi:10.1002/2015GL064751 (2015).

Matsuno, T., 1966: Quasi-geostrophic motions in the equatorial area. J. Meteor. Soc. Japan, 44, 25-43.

McCormick et al. 1995, Atmospheric effects of Mount Pinatubo, Nature

McCreary, J. P. Modelling wind-driven ocean circulation. JIMAR 80-0029, HIG 80-3, Univ. of Hawaii, Honolulu, pp. 64 (1980).

McGregor, S. and Timmermann, A. The effect of explosive tropical volcanism on ENSO. J. Climate 24, 21782191 (2011).

Mignot, J., Khodri, M., Frankignoul, C., and Servonnat, J. (2011). Volcanic impact on the Atlantic Ocean over the last millennium. Climate of the Past Discussions, 7, 2511-2554.

Murtugudde, R. G., Signorini, S. R., Christian, J. R., Busalacchi, A. J., McClain, C. R., and Picaut, J. (1999). 1998. Journal of Geophysical Research: Oceans, 104(C8), 18351-18366.

Murtugudde R, McCreary JP, Busalacchi AJ (2000) Oceanic processes associated with anomalous events in 
the Indian Ocean with relevance to 1997-1998. J Geophys Res 105:3295-3306

Ohba M., H. Shiogama, T. Yokohata, and M. Watanabe. Impact of strong tropical volcanic eruptions on ENSO simulated in a coupled GCM. J. Climate, 26, 5169-5182 (2013).

Pausata F.S.R., Christina Karamperidou, Rodrigo Caballero, David S. Battisti. (2016) ENSO response to high-latitude volcanic eruptions in the Northern Hemisphere: The role of the initial conditions. Geophysical Research Letters.

Rebert, J. P., Donguy, J. R., Eldin, G., and Wyrtki, K. (1985). Relations between sea level, thermocline depth, heat content, and dynamic height in the tropical Pacific Ocean. Journal of Geophysical Research: Oceans, 90(C6), 11719-11725.

Reverdin G, Cadet D, Gutzler D (1986) Interannual displacements of convection and surface circulation over the equatorial Indian Ocean. Q J R Meteorol Soc 112:43-46

Robock, A. Volcanic eruptions and climate. Rev. Geophys. 38, 191-219 (2000).

Saji NH, Goswami BN, Vinayachandran PN, Yamagata T (1999) A dipole mode in the tropical Indian Ocean. Nature 401:360-363.

Saji, N. H., Xie, S. P., and Yamagata, T. (2006). Tropical Indian Ocean variability in the IPCC twentiethcentury climate simulations. Journal of Climate, 19(17), 4397-4417

Samson G., S. Masson, F. Durand, P. Terray, S. Berthet and S. Jullien, 2016. Roles of land surface albedo and horizontal resolution on the Indian summer monsoon biases in a coupled ocean-atmosphere tropical-channel model. Clim Dyn., DOI 10.1007/s00382-016-3161-0

Schneider, D. P., C. M. Ammann, B. L. Otto-Bliesner, and D. S. Kaufman (2009), Climate response to large, high-latitude and low-latitude volcanic eruptions in the Community Climate System Model, J. Geophys. Res., 114, D15101, doi:10.1029/2008JD011222.

Schott, F. A., Xie, S. P., and McCreary, J. P. (2009). Indian Ocean circulation and climate variability. Reviews of Geophysics, 47(1).

Sprintall, J., and Révelard, A. (2014). The Indonesian Throughflow response to Indo-Pacific climate variability. Journal of Geophysical Research: Oceans, 119(2), 1161-1175.

Sobel, A. H., Nilsson, J., and Polvani, L. M. (2001). The weak temperature gradient approximation and balanced tropical moisture waves. Journal of the atmospheric sciences, 58(23), 3650-3665.

Soden, B. J., Wetherald, R. T., Stenchikov, G. L. and Robock, A. Global cooling after the eruption of mount pinatubo: a test of climate feedback by water vapor. Science 296, 727-730 (2002).

Stenchikov, G., Delworth, T. L., Ramaswamy, V., Stouffer, R. J., Wittenberg, A., and Zeng, F. (2009). Volcanic signals in oceans. Journal of Geophysical Research: Atmospheres, 114(D16).

Stevenson S., B. Otto-Bliesner, J. Fasullo, and E. Brady. "El Niño Like” Hydroclimate Responses to Last Millennium Volcanic Eruptions. J. Clim., DOI: 10.1175/JCLI-D-15-0239.1 (2016).

Suresh, I., Vialard, J., Lengaigne, M., Han, W., McCreary, J., Durand, F., and Muraleedharan, P. M. (2013). waveguide. Geophysical Research Letters, 40(21), 5740-5744. 
Suresh, I., Vialard, J., Izumo, T., Lengaigne, M., Han, W., McCreary, J., and Muraleedharan, P. M. (2016). Dominant role of winds near Sri Lanka in driving seasonal sea level variations along the west coast of India. Geophysical Research Letters, 43(13), 7028-7035.

Taylor K. E., R. J. Stouffer, and G. A. Meehl, 2012. An Overview of CMIP5 and the Experiment Design. Bull. Amer. Meteor. Soc., 93, 485-498

Vallivattathillam, P., Iyyappan, S., Lengaigne, M., Ethé, C., Vialard, J., Levy, M., ... and Naqvi, W. (2017). Positive Indian Ocean Dipole events prevent anoxia off the west coast of India. Biogeosciences, 14(6), 1541

Vecchi, G. A., and Soden, B. J. (2007). Global warming and the weakening of the tropical circulation. Journal of Climate, 20(17), 4316-4340.

Webster PJ, Moore A, Loschnigg J, Leban M (1999) Coupled dynamics in the Indian Ocean during 19971998. Nature 401:356-360

Xie, S.-P., H. Annamalai, F. Schott, and J. P. McCreary Jr., 2002: Origin and predictability of south Indian Ocean climate variability. J. Climate, 15, 864-874.

Yamagata, T., S. K. Behera, J.-J. Luo, S. Masson, M. R. Jury, and S. A. Rao, 2004: Coupled ocean-atmosphere variability in the tropical Indian Ocean. Earth's Climate: The Ocean-Atmosphere Interaction, Geophys. Monogr., Vol. 147, Amer. Geophys. Union, 189-212.

Zanchettin D., M. Khodri, C. Timmreck, M. Toohey, A. Schmidt, E. P. Gerber, G. Hegerl, A. Robock, F. S. Pausata, W. T. Ball, S. E. Bauer, S. Bekki, S. S. Dhomse, A. N. LeGrande, G. W. Mann, L. Marshall, M. Mills, M. Marchand, U. Niemeier, V. Paulain, A. Rubino, A. Stenke, K. Tsigaridis, and F. Tummon (2016) The Model Intercomparison Project on the climatic response to Volcanic forcing (VolMIP): Experimental design and forcing input data. GeoScientific Model Development discussion paper, MS No.: gmd-2016-68. Special Issue: Coupled Model Intercomparison Project Phase 6 (CMIP6) Experimental Design and Organization. 


\section{Figures captions}

514 Figure 1. Indian Ocean response in the autumn following a Pinatubo-like eruption.

515 (a) $2 \mathrm{~m}$ air temperature (T2 $\mathrm{m}$, in ${ }^{\mathrm{o}} \mathrm{C}$, shading) and surface wind stress $\left(\mathrm{N} \mathrm{m}^{-2}\right.$, vectors) 516 difference between PTUBO and CTL ensemble coupled experiments (CPL) in autumn 517 (September-November), a few months after the eruption in June. (b) as in (a), but for the 518 ALL AGCM $\left({ }^{\circ} \mathrm{C}\right)$. (c) as (a), but for the SSH (cm) response. (d) SSH response in an LCS 519 model experiment forced by PTUBO-CTL wind stress anomalies (cm). 90\% significance 520 level in black contours (dashed when negative values), except in (a) in which red/green 521 contours show positive/negative relative SST $\left({ }^{\circ} \mathrm{C}\right)$. Windstress overlaid in black when $52290 \%$ significant, grey otherwise.

524 Figure 2. Main mechanisms driving the IO response. Equatorial IO zonal wind stress 525 (upper row, N.m-2) and eastern equatorial IO SSH response in the LCS (middle row, $\mathrm{cm}$ ) 526 for (left) CPL (black) and ALL (purple) experiments and for (right) LAND (cyan), 527 LAND_Africa (green), OCEAN (dark blue) and ATM (red) sensitivity experiments. Circles 528 indicate when anomalies are significant at the 90\% level. Light color shading indicate 529 the 90\% confidence interval for selected experiments. Zonal wind stress is averaged 530 over $\left[60^{\circ} \mathrm{E}-90^{\circ} \mathrm{E} ; 2.5^{\circ} \mathrm{N}-2.5^{\circ} \mathrm{S}\right]$ region and $\mathrm{SSH}$ over the $\left[90^{\circ}-110^{\circ} \mathrm{E} ; 0^{\circ}-10^{\circ} \mathrm{S}\right]$ region.

532 Fig. 3. Influence of background IO conditions on the IPSL CM5B response to the 533 eruption. (a) SST DMI anomaly (with regards to historical run climatology, in ${ }^{\circ} \mathrm{C}$ ) for the 534 control ensemble members (black) and the Pinatubo simulations (purple) for members 535 showing neutral IOD conditions in SON 1991 in the control simulations (49 members).

536 (b) Same for positive IOD conditions (21 members). (c) Same for negative IOD 537 conditions (20 members). d, e, f: same for DMI east pole SSH. $90 \%$ intervals of 538 confidence in light shading.

Fig. 4. IO response in the autumn following tropical volcanic eruptions in CMIP models. CMIP response to the last five large tropical eruptions in SON of eruption's year

542 for (a) $2 \mathrm{~m}$ air temperature $\left({ }^{\circ} \mathrm{C}\right.$, positive/negative relative SST in red/green contours), 543 (b) SSH (cm) and (c) Primary production (PP, unit : 10-8 $\mathrm{mol} \mathrm{m}^{-2} \mathrm{~s}^{-1}$ ). Wind stress are 544 overlaid in black when 90\% significant, grey otherwise. 90\% significance level in black 545 contours (dashed when negative values), except for PP, whis is available for less models, 
546 for which significancy is defined when there are two times more models of the adequate 547 sign by solid color shading (white-stripped when not significant). 
Figures 1 to 4 with captions. 

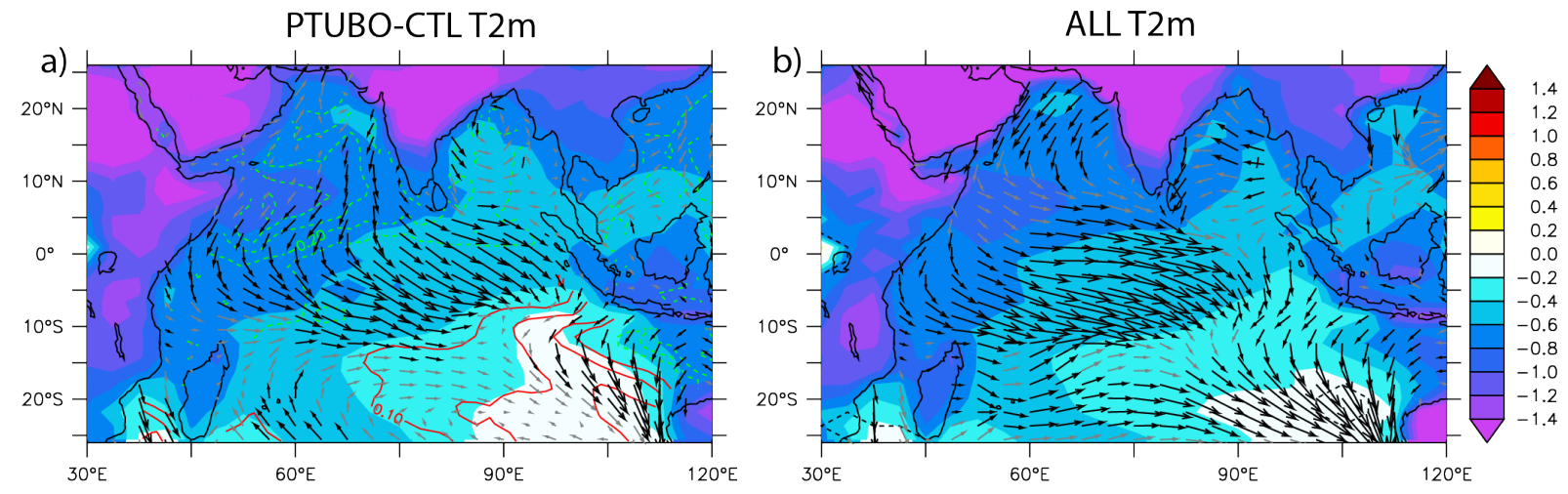

PTUBO-CTL SSH
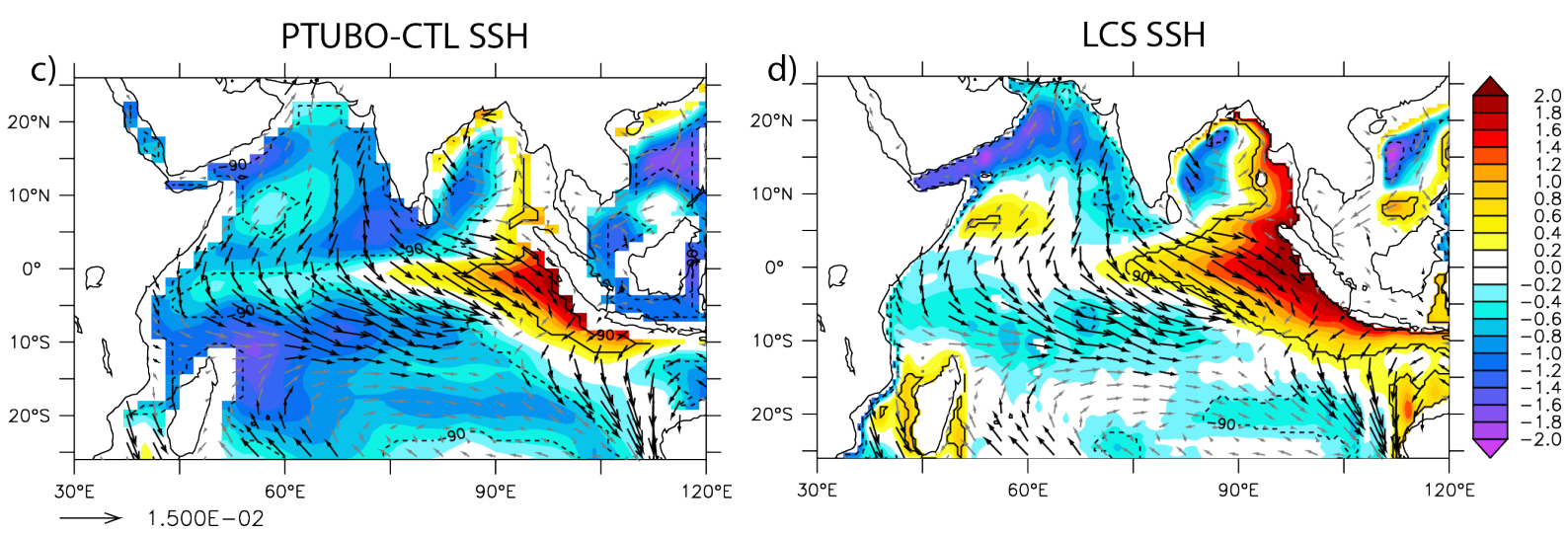

Figure 1. Indian Ocean response in the autumn following a Pinatubo-like eruption.

(a) $2 \mathrm{~m}$ air temperature $\left(\mathrm{T} 2 \mathrm{~m}\right.$, in ${ }^{\circ} \mathrm{C}$, shading) and surface wind stress $\left(\mathrm{N} \mathrm{m}^{-2}\right.$, vectors) difference between PTUBO and CTL ensemble coupled experiments (CPL) in autumn (September-November), a few months after the eruption in June. (b) as in (a), but for the ALL AGCM $\left({ }^{\circ} \mathrm{C}\right)$. (c) as (a), but for the SSH (cm) response. (d) SSH response in an LCS model experiment forced by PTUBO-CTL wind stress anomalies (cm). 90\% significance

8 level in black contours (dashed when negative values), except in (a) in which red/green 9 contours show positive/negative relative SST $\left({ }^{\circ} \mathrm{C}\right)$. Windstress overlaid in black when $1090 \%$ significant, grey otherwise. 

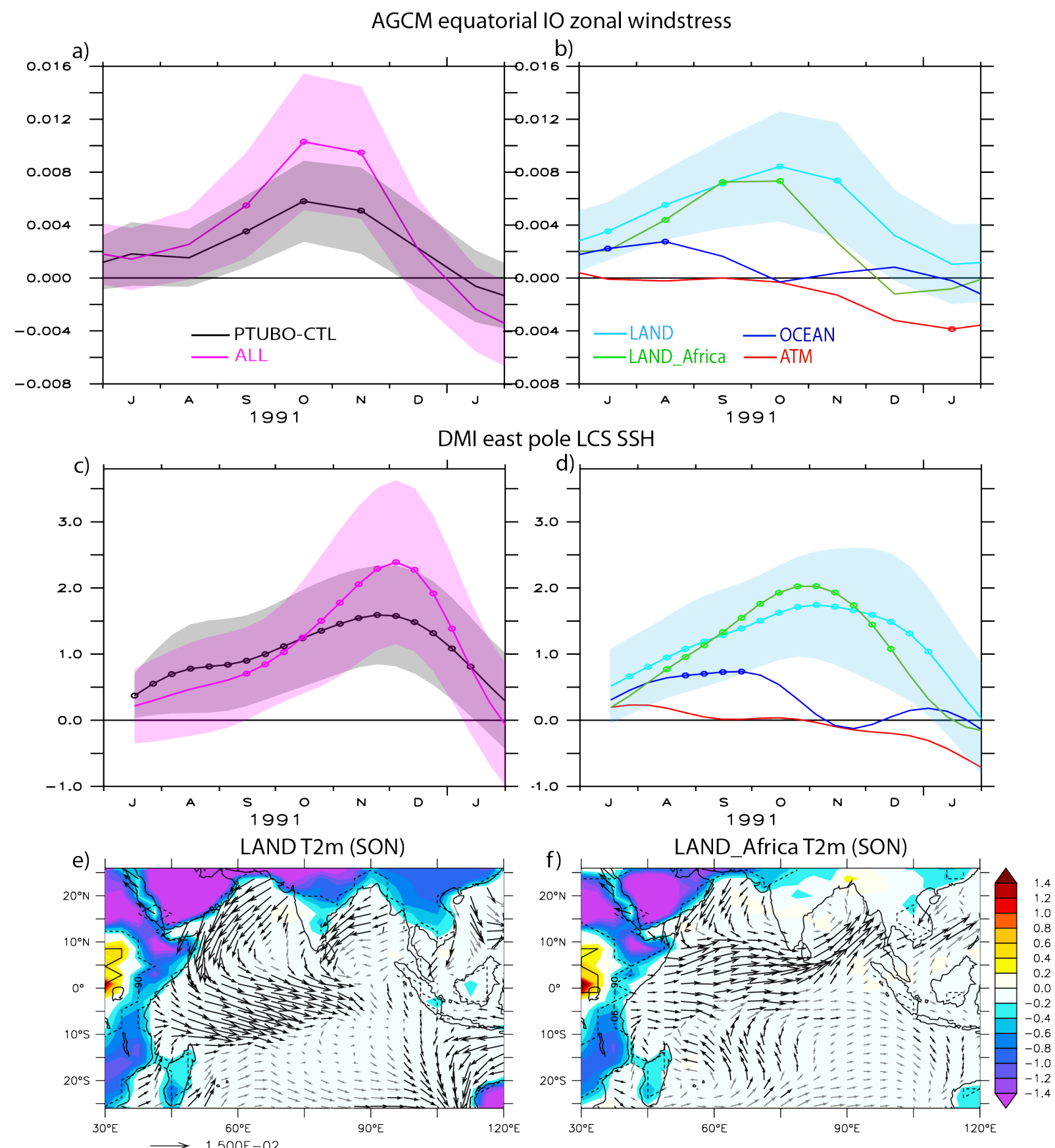

Figure 2. Main mechanisms driving the IO response. Equatorial IO zonal wind stress

13 (upper row, N. $\mathrm{m}^{-2}$ ) and eastern equatorial IO SSH response in the LCS (middle row, $\mathrm{cm}$ )

14 for (left) CPL (black) and ALL (purple) experiments and for (right) LAND (cyan),

15 LAND_Africa (green), OCEAN (dark blue) and ATM (red) sensitivity experiments. Circles

16 indicate when anomalies are significant at the $90 \%$ level. Light color shading indicate

17 the $90 \%$ confidence interval for selected experiments. Zonal wind stress is averaged

18 over $\left[60^{\circ} \mathrm{E}-90^{\circ} \mathrm{E} ; 2.5^{\circ} \mathrm{N}-2.5^{\circ} \mathrm{S}\right]$ region and $\mathrm{SSH}$ over the $\left[90^{\circ}-110^{\circ} \mathrm{E} ; 0^{\circ}-10^{\circ} \mathrm{S}\right]$ region. 

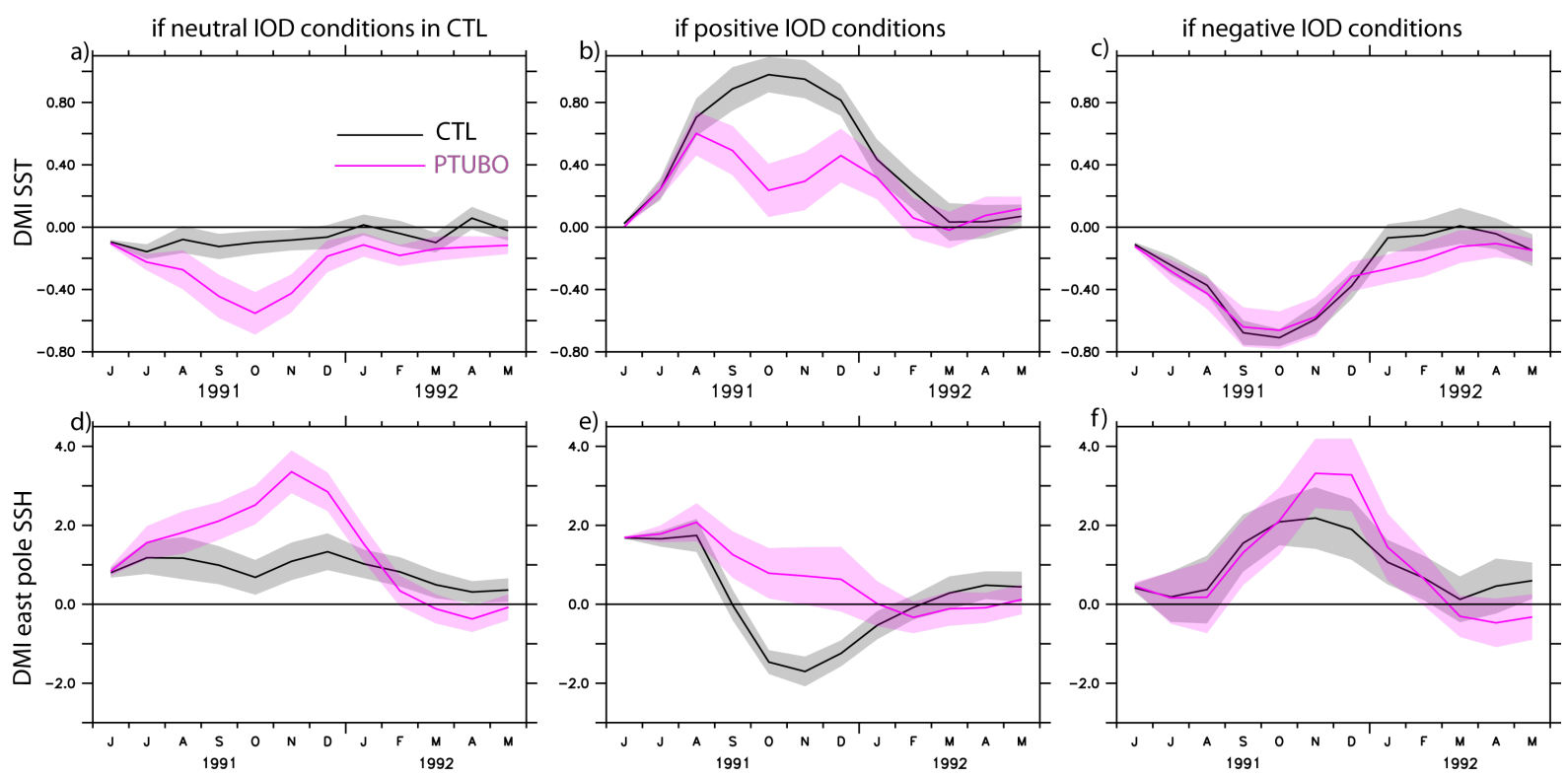

Fig. 3. Influence of background IO conditions on the IPSL CM5B response to the eruption. (a) SST DMI anomaly (with regards to historical run climatology, in ${ }^{\circ} \mathrm{C}$ ) for the control ensemble members (black) and the Pinatubo simulations (purple) for members showing neutral IOD conditions in SON 1991 in the control simulations (49 members). (b) Same for positive IOD conditions (21 members). (c) Same for negative IOD conditions $(20$ members). d, e, f: same for DMI east pole SSH. $90 \%$ intervals of confidence in light shading. 

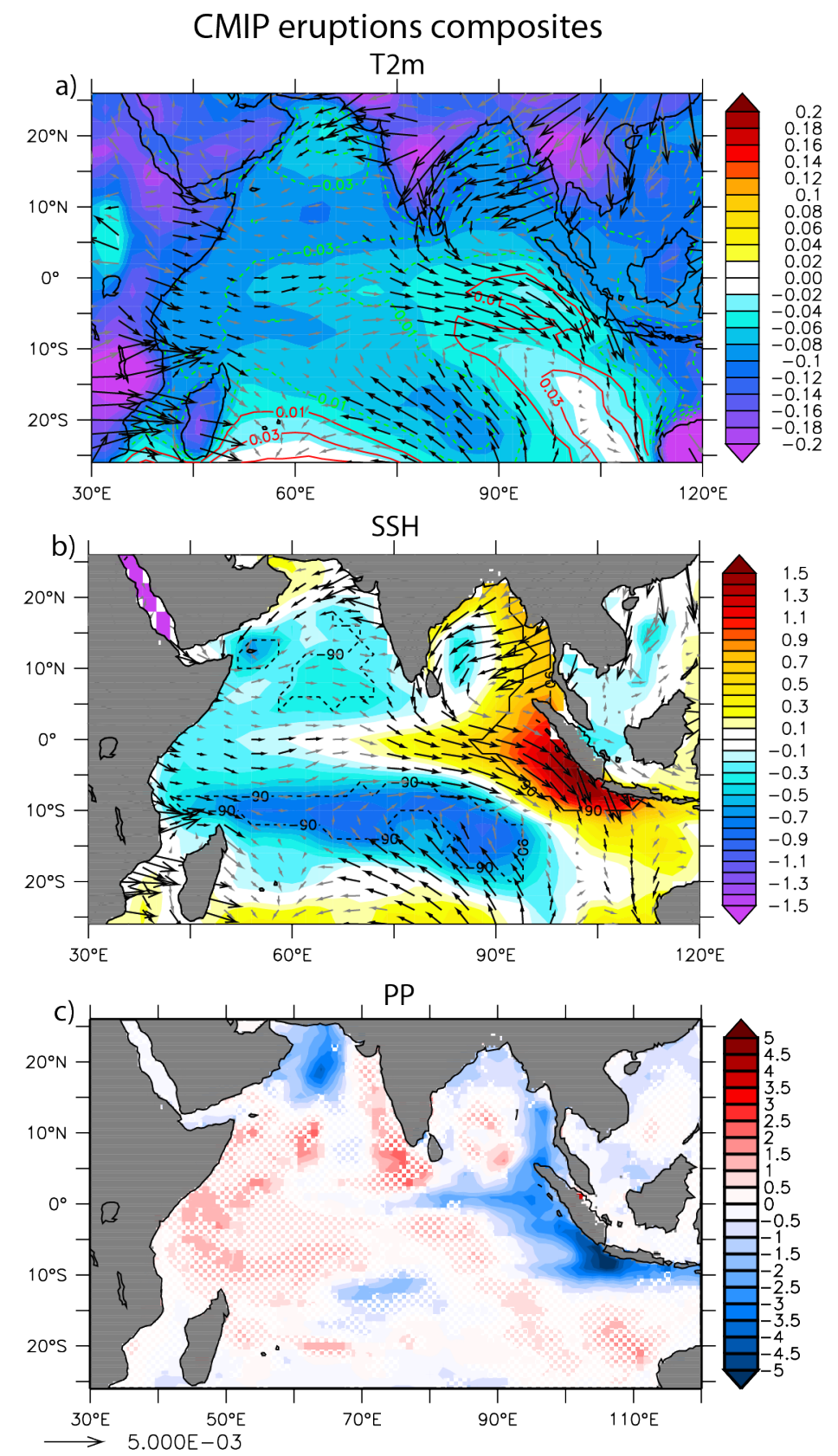

Fig. 4. IO response in the autumn following tropical volcanic eruptions in CMIP

30 models. CMIP response to the last five large tropical eruptions in SON of eruption's year for (a) $2 \mathrm{~m}$ air temperature $\left({ }^{\circ} \mathrm{C}\right.$, positive/negative relative SST in red/green contours), (b) SSH (cm) and (c) Primary production (PP, unit : $10^{-8} \mathrm{~mol} \mathrm{~m}^{-2} \mathrm{~s}^{-1}$ ). Wind stress are overlaid in black when $90 \%$ significant, grey otherwise. $90 \%$ significance level in black contours (dashed when negative values), except for PP, whis is available for less models, for which significancy is defined when there are two times more models of the adequate sign by solid color shading (white-stripped when not significant). 


\section{Supplementary Information for "A subsurface Indian Ocean Dipole response to tropical volcanic eruptions"}

Takeshi Izumo, Myriam Khodri, Matthieu Lengaigne, Iyyappan Suresh

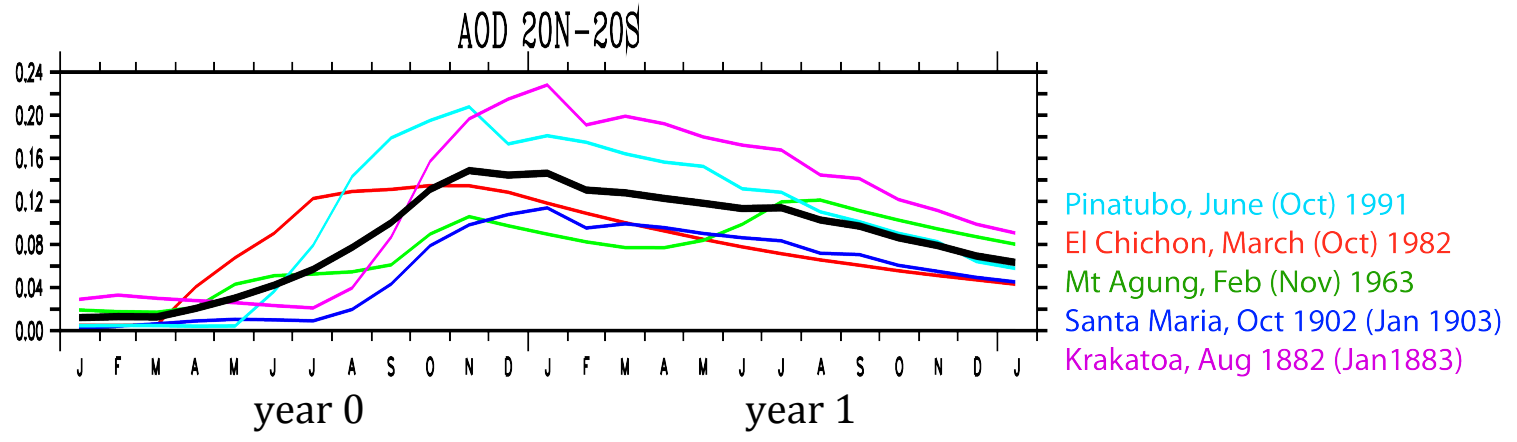

Figure S1. Tropical average $\left(20^{\circ} \mathrm{N}-20^{\circ} \mathrm{S}\right)$ of Stratospheric Aerosol Optical Depth (AOD ; Gao et al. 2008) for the last 5 tropical stratospheric eruptions from the historical period, from year 0 (year of the eruption) to year 1 (eruption's following year). The starting (peaking) month and year for each eruption is indicated on the right-hand side. The black line indicates the mean of the 5 eruptions. This figure illustrates the large diversity in tropical AOD amplitude, seasonality and temporal evolution, and the fact that the Pinatubo eruption had the largest radiative forcing in summer-fall, the season that matters for the development of the subsurface IOD studied here.
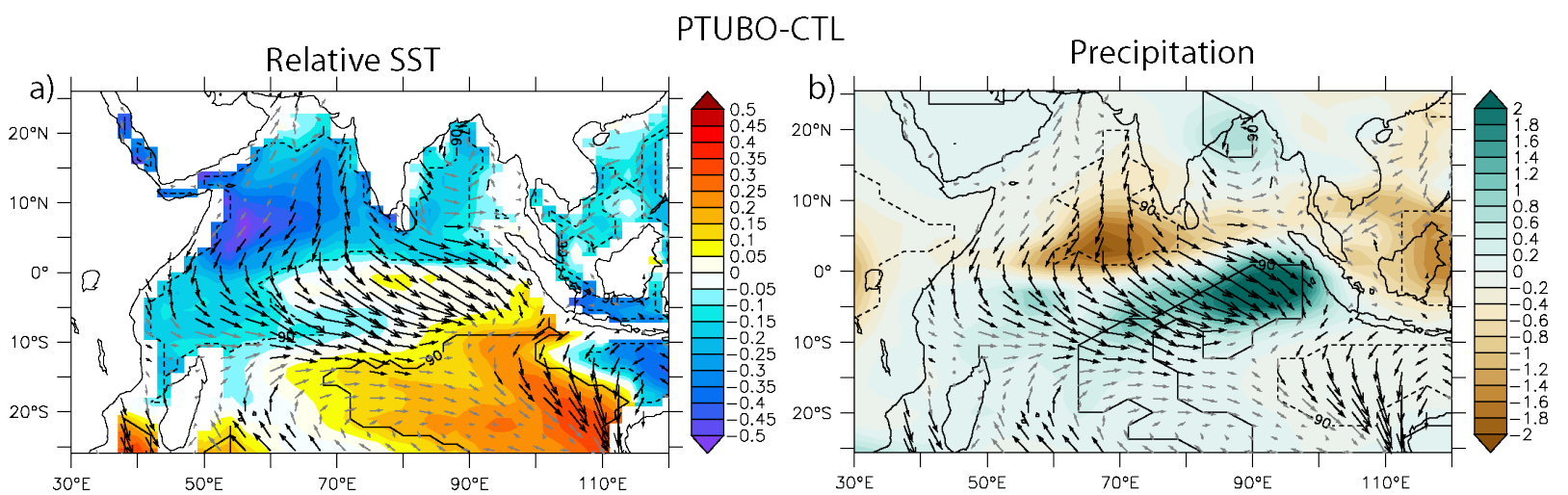

Figure S2. As Fig. 1a (difference PTUBO-CTL), but for (a) relative SST $\left({ }^{\circ} \mathrm{C}\right.$ ) and $(\mathrm{b})$ precipitation (mm/day). 

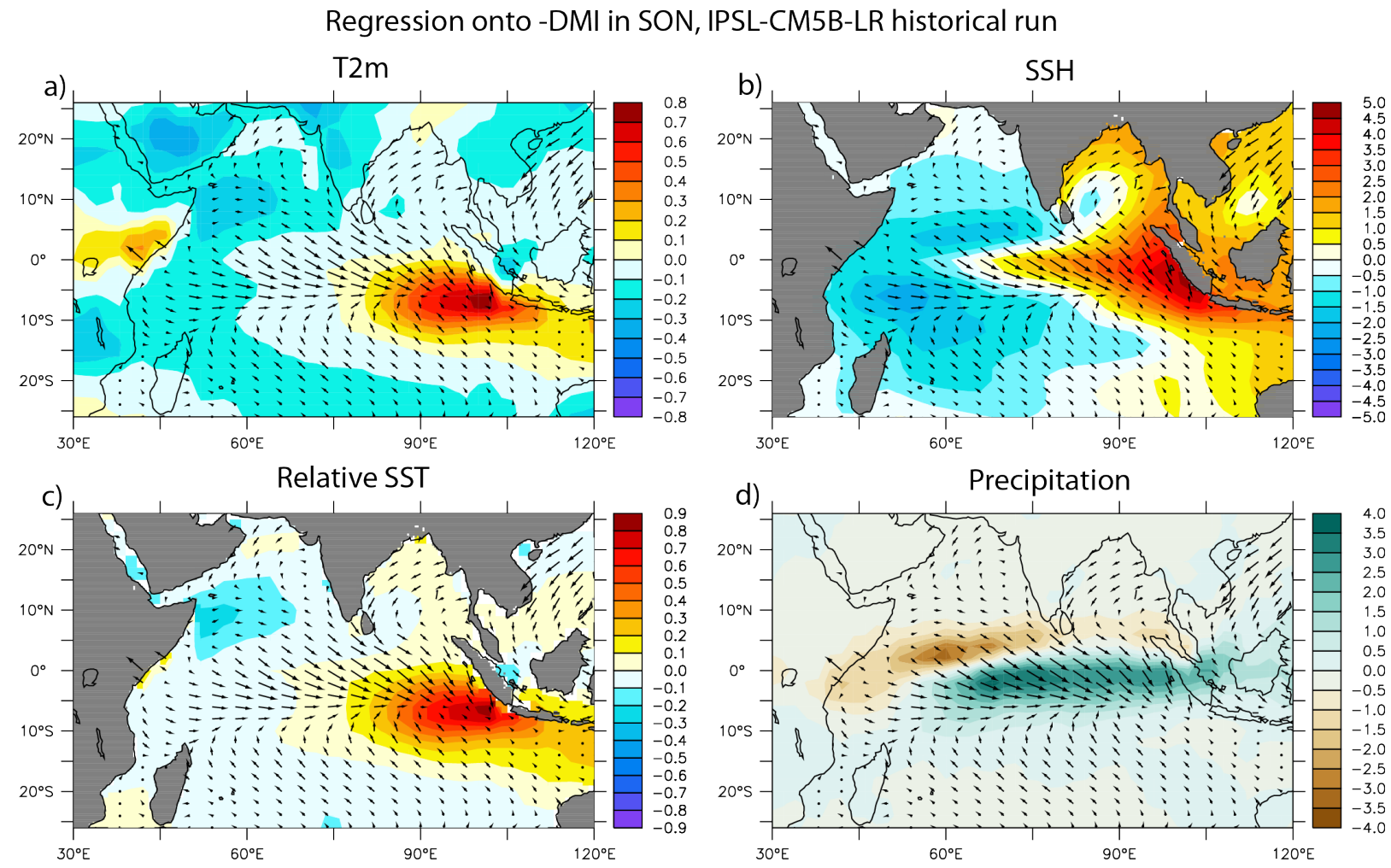

Figure S3. Typical IOD pattern in IPSL-CM5B-LR. Regression of (a) $2 \mathrm{~m}$ air temperature $\left({ }^{\circ} \mathrm{C}\right)$, (b) SSH $(\mathrm{cm})$, (c) relative SST $\left({ }^{\circ} \mathrm{C}\right)$ and $(\mathrm{d})$ precipitation $(\mathrm{mm} /$ day) onto normalised DMI in SON (its standard deviation being $0.55^{\circ} \mathrm{C}$ ), in IPSL-CM5B-LR CMIP5 historical run.
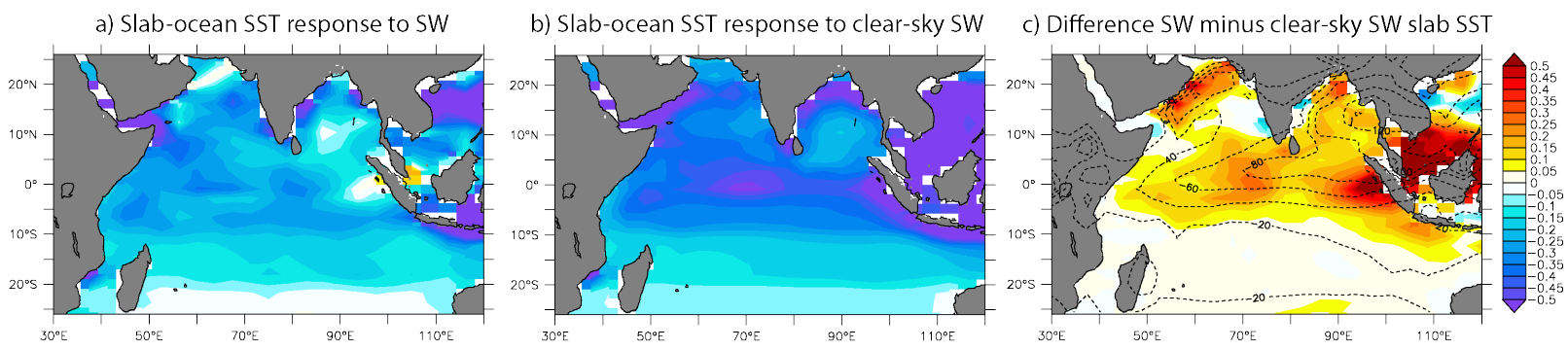

Figure S4. Slab ocean response to PTUBO-CTL SW forcing in July-September (JAS, when OCEAN has a significant effect on equatorial zonal wind stress; cf. Fig. 2). (a) Slabocean SST response to PTUBO-CTL SW forcing $\left({ }^{\circ} \mathrm{C}\right)$. (b) Slab-ocean SST response to clearsky PTUBO-CTL SW forcing. (c) Difference between the two, SW minus clear-sky SW, i.e. mainly the effect of climatological cloud cover shown in contours (effect inferred from IPSL-CM5B-LR climatological SW minus climatological clear-sky SW; W. ${ }^{-2}$ ). See details about this slab ocean using a spatially-varying MLD climatology in supplementary section 3. Note that, while the cooling and its heterogeneity is mainly due to the SW anomalies, there is a notable additional effect of latent heat flux - through windspeed anomalies that could explain the relative SST warming seen south of $10^{\circ} \mathrm{S}$ in the southeast Indian Ocean, west of Australia, in Fig. S2a and Fig. 1a. The northwest anomalies there (possibly related to the anticyclonic anomalies created by the strong land cooling of Australia; not shown) oppose the trade winds, thereby decreasing local windspeed and evaporation. A similar windspeed effect, but of opposite sign, seems to have also played a role in reinforcing the Arabian Sea cooling (southwesterly anomalies reinforcing the monsoon lowlevel jet in JAS; not shown). 


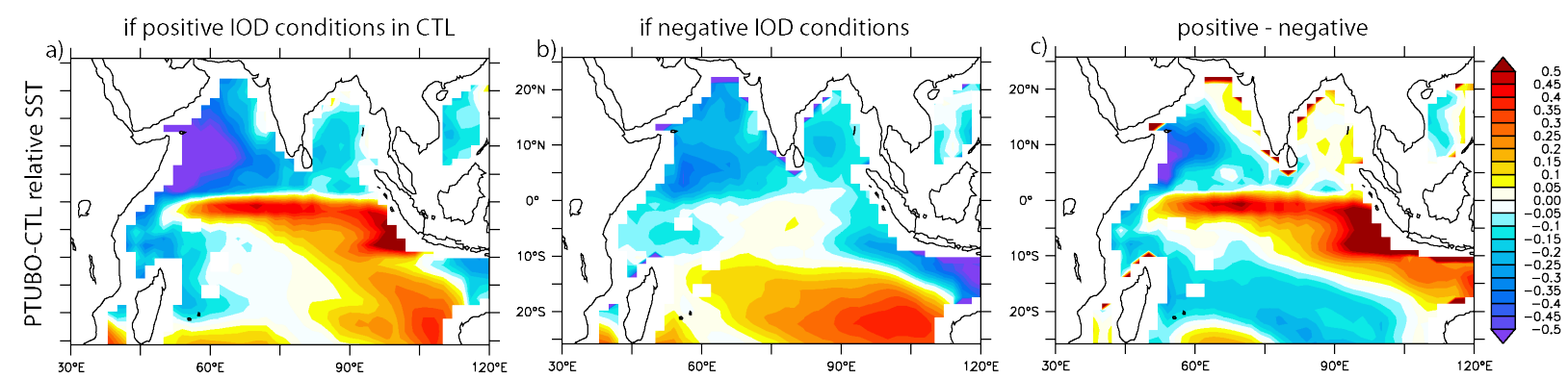

Figure S5. Influence of background IO conditions on the IPSL CM5B relative SST response. (a) As Fig. S2a, but for members showing positive IOD conditions in SON 1991 in the control simulations. (b) same for negative IOD conditions. (c) difference between panels $\mathrm{b}$ and $\mathrm{a}$. This figure highlights the asymmetries in the SST response, with a much larger negative Northwest-Southeast SST gradient in the background positive IOD case, which projects onto the DMI poles (cf. Fig. 3a,b,c).

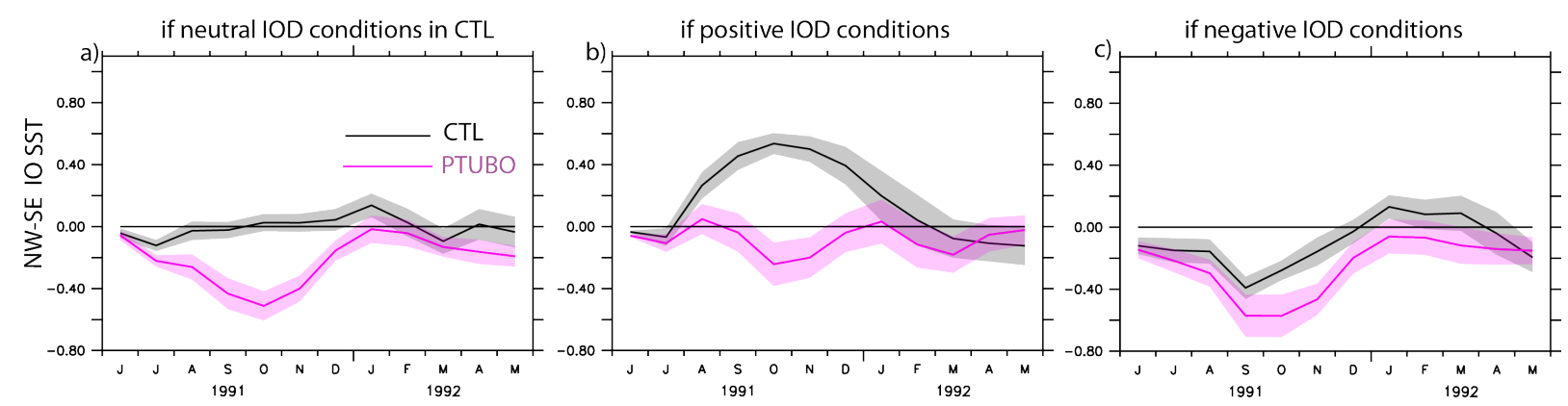

Figure S6. Influence of background IO conditions on the IPSL CM5B NW-SE SST gradient response. (a) As Fig. 3abc, but for an index especially developped to capture the Northwest - Southeast (NW-SE) SST gradient forced by the eruption, defined as the SST difference between the $50-70^{\circ} \mathrm{E}, 20^{\circ} \mathrm{N}-0^{\circ} \mathrm{N}$ and $90-110^{\circ} \mathrm{E}, 0-20^{\circ} \mathrm{S}$ regions. The PTUBO-CTL difference is even larger than for the DMI shown in Fig. 3abc, and is still significant in the negative IOD background case. 


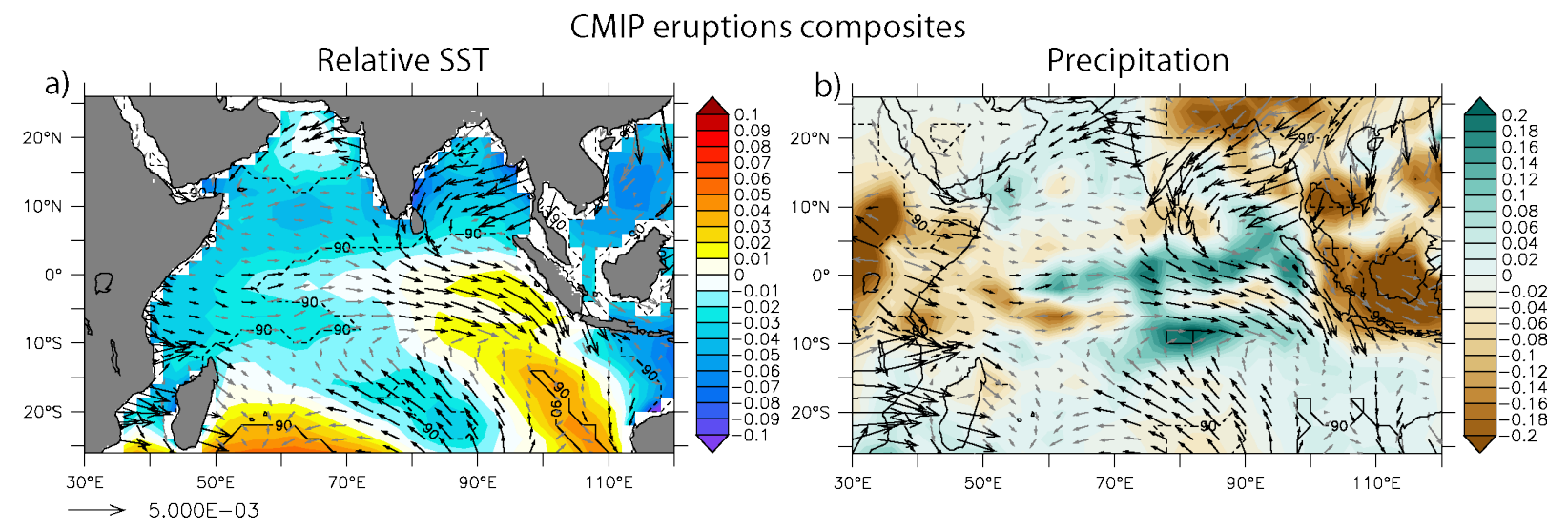

Figure S7. As Fig. 4 (CMIP eruptions composites), but for (a) relative SST $\left({ }^{\circ} \mathrm{C}\right.$ ) and (b) precipitation ( $\mathrm{mm} /$ day).

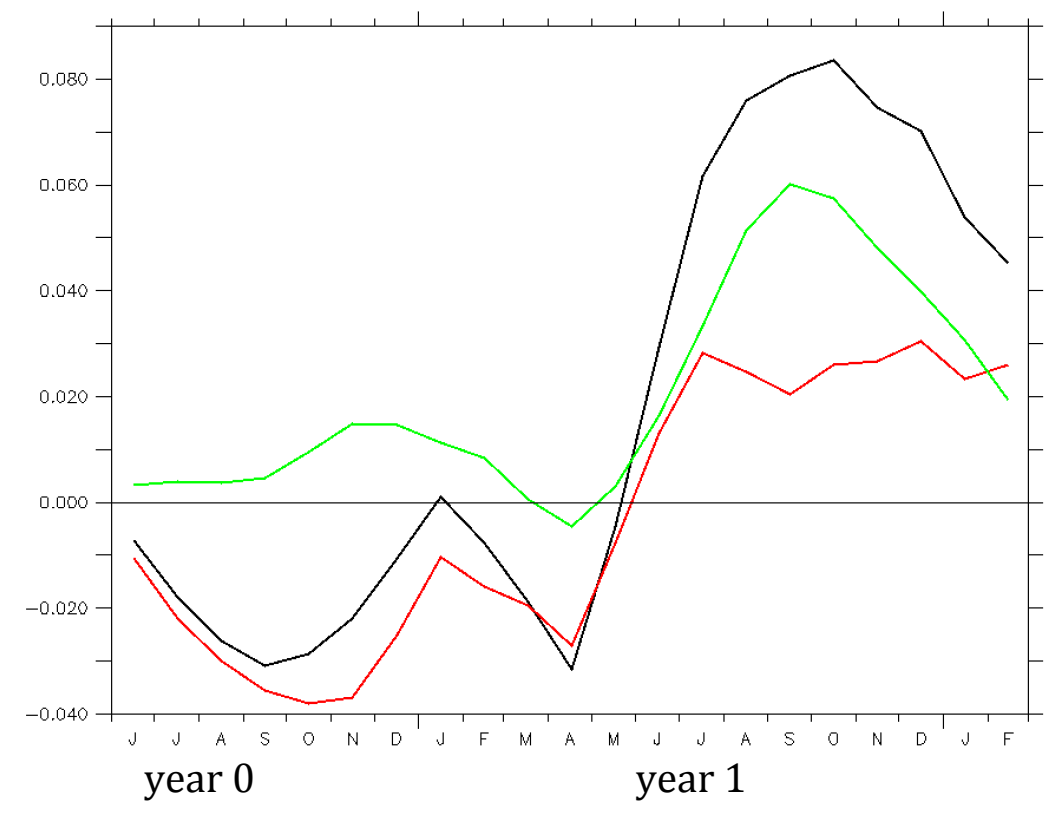

Fig. S8: DMI temporal evolution from year 0 to year 1 in CMIP MME (black), external influence of ENSO on the DMI (green; inferred from the linear regression of DMI on Nino3.4 SST computed for each CMIP model separately), and the DMI response independent of simultaneous ENSO conditions (red = black - green). 


\section{Inhomogeneous cooling, relative SST and rainfall responses to eruptions}

To understand the rainfall response, as the eruption induces an overall cooling, especially in the tropics, it is relevant to use the relative SST, simply defined as the SST minus its tropical mean $\left(20^{\circ} \mathrm{N}-20^{\circ} \mathrm{S}\right)$, a concept initially developped for global warming (Held and Soden 2006, Vecchi and Soden 2007), but which is also relevant here, as the volcanic aerosol optical depth radiative forcing is rather homegeneous zonally along the tropical band and evolves relatively slowly with regards to tropospheric tropical adjustment time (see also K17, which shows the relevance of using relative SST to understand the El Niño response to tropical eruptions).

Concerning the physical process behind the faster land cooling than ocean one, it is likely related to the larger lapse rate over the land, as the troposphere over the land generally is drier than that over the oceans (as suggested by global warming studies, e.g. Joshi et al., 2008), rather than to the lower heat capacity of the land (as suggested by some earlier studies for volcanism). The upper tropospheric cooling is relatively uniform in the tropics: a larger lapse rate hence yields a larger surface cooling over land, in particular in dry areas (same suggested mechanism, for a cooling instead of a warming, as in the case of global warming discussed in e.g. Sobel et al., 2001; Joshi et al. 2008).

\section{The IPSL-CM5B-LR model and the AGCM experimental strategy (detailed description)}

In the present study, we use the same set of simulations as in K17 including experiments with the Institut Pierre Simon Laplace (IPSL) CM5B-LR coupled climate model, atmospheric and oceanic sensitivity ensemble experiments, with and without a Pinatubo-like forcing, to identify the main mechanisms at play. We choose the Pinatubo eruption (June 15th 1991 ), as it is the largest and best-documented tropical stratospheric eruption of the instrumental period. The details of these experiments are already described in K17 and we only summarize here their salient features. The atmospheric component is LMDZ5B (Hourdin et al. 2013) with 39 pressure levels (including 18 in the stratosphere) and a horizontal resolution of $1.87^{\circ}$ in latitude and $3.75^{\circ}$ in longitude. It uses ORCHIDEE as its land surface component. It is coupled to the NEMO3.2 oceanic component (Madec 2015) (31 vertical levels, and an horizontal resolution of about $2^{\circ}$, with a refinement of the latitudinal resolution to $0.5^{\circ}$ near the equator; ORCA2 grid). This model is able to capture reasonably well the main observed IOD features (Jourdain et al. 2016).

The above IPSL-CM5B-LR climate model is forced by Pinatubo stratospheric aerosol optical depth (AOD) data provided by Gao et al. (2008). The 30-member ensemble experiment is run from $1^{\text {st }}$ of June of a selected year from the historical run, chosen to be close to 1990s greenhouses gases and tropospheric aerosols concentrations, to lie more than 5 years away from any volcanic eruption and to lead to neutral El Nino Southern Oscillation (ENSO) conditions in the absence of volcanic forcing, avoiding any interference with external ENSO forcing (K17). For this initial state, 30 members were generated by adding a small white noise on the initial SST. For Fig. 3, we used two others 30-member ensemble experiments starting from the $1^{\text {st }}$ June of two other selected years, these two years being characterized respectively by El Niño and La Niña conditions in the Pacific. 
Corresponding control ensembles starting from the same initial conditions but without Pinatubo volcanic forcing were analysed (i.e. 3 CTL ensembles of 30 members each).

K17 have developed targeted ensemble experiments using the atmospheric component of the IPSL-CM5B model forced by the outputs of the coupled model ensemble (see K17 for details) to investigate the respective role of the following three processes in the generation of atmospheric anomalies, notably windstress :

(1) the direct effect of volcanic radiative forcing on clouds and atmospheric vapour content (Soden et al. 2002), potentially altering the atmospheric vertical structure and inducing an atmospheric dynamical response (referred to as ATM). Volcanic aerosol forcing is included in ATM, but the surface albedo is modified so that continental surfaces do not cool in response to volcanic forcing in this experiment.

(2) the indirect effects of volcanic forcing through the SST cooling and its spatial heterogeneities, and related horizontal SST gradients (OCEAN; inferred from the difference between the AGCM forced by the SST from PTUBO experiment and the unperturbed AGCM experiment, cf. K17). The OCEAN experiment includes not only the effect of SST anomalies that develop in response to volcanic forcing, i.e. the initial thermodynamical forcing and the slab ocean response, but also the positive Bjerkness feedback (i.e. the LCS dynamical response) once nIOD-like relative SST anomalies have started developing. However, the dominance of the LAND process (cf. Fig. 2) suggests that coupling processes, notably the Bjerknes feedback, should only be of secondary importance during the summer-fall of the eruption year, at least in our experimental framework.

(3) continents cool faster than the ocean in response to volcanic forcing. The third and last experiment (referred to as LAND) tests the effect of this differential surface cooling between land and ocean. In LAND, there is no prescribed aerosol forcing as in OCEAN, but the land surface albedo modification enforces a land surface cooling that is consistent with that of the IPSL-CM5B coupled model experiment.

This strategy allows land surface temperature variations in OCEAN experiments, in response to SST anomalies, as described in the context of global warming (Compo and Sadershmukh 2009, Dommenget 2009). It is hence more physically consistent than experiments that directly constrain land surface temperature (Ohba et al. 2013), which can result in an exaggerated land cooling and land-ocean gradients. An additionnal sensitivity experiment from K17, of interest here, explores the effect of the faster land cooling only over one specific region, Africa (LAND-Africa). An additional experiment (ALL) that includes all three LAND, OCEAN and ATM processes reproduces reasonably well the anomalies simulated by the IPSL-CM5B ensemble simulation (Fig. 1a,b and Fig. $2 \mathrm{a}, \mathrm{c})$, confirming the relevance of this two-tier approach for understanding how volcanic eruptions induce equatorial IO westerlies. 


\section{Linear Continuously Stratified (LCS) model and slab ocean model}

The equatorial Indian Ocean dynamical oceanic response to wind-stress anomalies resulting from each process is estimated separately by forcing a linear continuously stratified (LCS; McCreary, 1980) ocean model of the Indo-Pacific region (same configuration as in Izumo et al. 2016, 2018). This LCS model, that resolves vertical baroclinic modes (with mainly the first two modes contributing; not shown), realistically simulates SSH anomalies (see Suresh et al. 2013, 2016 ; Izumo et al. 2016, 2018; K17 for further details).

A simple slab ocean mixed layer equation is also used, to simulate the SST thermodynamical response to the eruption-induced ShortWave (SW) flux anomalies (see Supplementary Information), following the approach of McGregor and Timmerman (2011). This simple slab ocean mixed layer equation is based on the following linear SST equation to realistically resolve the variations of SST forced by Pinatubo shortwave anomalies (SW'):

$$
\frac{d S S T T^{\prime}}{d t}=S W^{\prime} /\left(\rho C_{p} M L D\right)-\alpha S S T^{\prime}
$$

the "prime" denoting the Pinatubo-forced anomalies (i.e. Pinatubo-forced IPSL PTUBO run minus control IPSL CTL run). SW is here the SW surface net downward flux minus the downward SW at the bottom of the mixed layer. Mixed Layer Depth (MLD) is the local MLD monthly climatology, inferred from the depth at which the potential density is $0.06 \mathrm{~kg} / \mathrm{m}^{3}$ larger than at $10 \mathrm{~m}$ depth (equivalent to a $0.2^{\circ} \mathrm{C}$ decrease in temperature) of the CTL IPSL run. The forcing is simply from this SW', other heat fluxes being parameterised as a constant Newtonian damping $-\alpha S S T^{\prime}$, with the typical damping timescale $1 / \alpha=2$ months, as in Izumo et al. (2016). The time integration (with initial start in June 1991) of the above linearized SST tendency equation gives us the $S S T^{\prime}$ temporal evolution. A reference simulation is set up using the MLD climatology and the SW' anomalies induced by Pinatubo in IPSL ensemble mean. In addition to the clear-sky sensitivity experiment (in which the clear-sky SW forcing is rather zonally-homogeneous in the tropical band) shown in Figure S4, we used this very simple model to evaluate the roles of the zonal variations of SW' (mainly related to climatological cloud cover/albedo spatial variations) and of mean MLD zonal variations on the SST response to Pinatubo, and so on SST zonal gradient. While the former explains most of the actual gradient, the latter does not: the zonal variations of the MLD climatology have less impact on equatorial SST gradient (not shown) and generally oppose those from climatological cloud cover distribution (MLD, being shallower in the east, will tend to increase cooling there).

\section{CMIP5 simulations}

To assess the robustness of our results with our single model experiments, we also analyse historical simulations from the Climate Model Intercomparison Project phase 5 (CMIP5) dataset (Taylor et al. 2012) over the 1861-2005 period (see Suppl. Table S1). To estimate their responses to tropical volcanism, we composited the 5 largest tropical eruptions (cf. K17 for details). 49 models were available for $2 \mathrm{~m}$ and surface temperature, 44 for windstress, 37 for SSH and 18 for Primary Productivity. We used all models available for each field. The Multi-Model-Ensemble (MME) mean is computed by first 
averaging all members for each model to smooth out internal noise before averaging between models. We checked that the results are qualitatively insensitive to the choice of these methods: using the first member of each model, or reducing the number of models, gives similar results, but with slightly more internal noise.

In preprocessing, we removed the 10 previous years sliding climatology in CMIP historical runs, to filter out possible trends and interdecadal variability. 3 months running mean (for maps) or Hanning filter (for time series) is applied on data to reduce the strong intraseasonal variability of the tropics. In order to better compare models, which possibly have different typical interannual variations, we also computed «standardised" amplitudes of some relevant indices, by normalizing by the interannual standard deviation computed for Sept.-Nov. (SON) over the full historical run period and for each model.

In addition to the main analyses shown in the present paper, we have also done a CMIP inter-eruption comparison. We have compared various eruptions in CMIP in terms of impacts on the IO. At least all the eruptions had a subsurface negative IOD in SON0, except for Krakatau with neutral IOD in autum of yr0 (eruption in August, possibly too late to trigger a negative IOD; not shown), even if there is a large inter-model diversity because of the sensitivity to initial conditions (and so to internal variability of each model/member) that lowers the signal to noise ratio. 
Table S1. List of the 48 CMIP models (158 members) used in this study, and the maximum number of members in each model (mainly for surface air temperature at $2 \mathrm{~m}$ and sea level height).

\begin{tabular}{|c|c|c|}
\hline Institute name & Model name & Max. number of members \\
\hline \multirow[t]{2}{*}{$\mathrm{BCC}$} & bcc-csm1-1 & 3 \\
\hline & bcc-csm1-1-m & 3 \\
\hline BNU & BNU-ESM & 1 \\
\hline CCCma & CanESM2 & 5 \\
\hline \multirow[t]{3}{*}{ CMCC } & CMCC-CESM & 1 \\
\hline & CMCC-CM & 1 \\
\hline & CMCC-CMS & 1 \\
\hline \multirow{2}{*}{ CNRM-CERFACS } & CNRM-CM5 & 10 \\
\hline & CNRM-CM5-2 & 1 \\
\hline \multirow[t]{2}{*}{ CSIRO-BOM } & ACCESS1-0 & 1 \\
\hline & ACCESS1-3 & 3 \\
\hline CSIRO-QCCCE & CSIRO-Mk3-6-0 & 10 \\
\hline FIO & FIO-ESM & 3 \\
\hline ICHEC & EC-EARTH & 9 \\
\hline INM & inmem4 & 1 \\
\hline \multirow[t]{3}{*}{ IPSL } & IPSL-CM5A-LR & 6 \\
\hline & IPSL-CM5A-MR & 3 \\
\hline & IPSL-CM5B-LR & 1 \\
\hline LASG-CESS & FGOALS-g2 & 1 \\
\hline LASG-IAP & FGOALS-s2 & 1 \\
\hline \multirow[t]{3}{*}{ MIROC } & MIROC5 & 5 \\
\hline & MIROC-ESM & 3 \\
\hline & MIROC-ESM-CHEM & 1 \\
\hline \multirow[t]{3}{*}{$\mathrm{MOHC}$} & HadCM3 & 10 \\
\hline & HadGEM2-CC & 3 \\
\hline & HadGEM2-ES & 4 \\
\hline \multirow[t]{3}{*}{ MPI-M } & MPI-ESM-LR & 3 \\
\hline & MPI-ESM-MR & 3 \\
\hline & MPI-ESM-P & 2 \\
\hline \multirow[t]{2}{*}{ MRI } & MRI-CGCM3 & 3 \\
\hline & MRI-ESM1 & 3 \\
\hline \multirow[t]{4}{*}{ NASA-GISS } & GISS-E2-H & 6 \\
\hline & GISS-E2-H-CC & 1 \\
\hline & GISS-E2-R & 6 \\
\hline & GISS-E2-R-CC & 1 \\
\hline NCAR & CCSM4 & 6 \\
\hline \multirow[t]{2}{*}{ NCC } & NorESM1-M & 3 \\
\hline & NorESM1-ME & 1 \\
\hline NIMR-KMA & HadGEM2-AO & 1 \\
\hline \multirow[t]{4}{*}{ NOAA-GFDL } & GFDL-CM2p1 & 10 \\
\hline & GFDL-CM3 & 5 \\
\hline & GFDL-ESM2G & 1 \\
\hline & GFDL-ESM2M & 1 \\
\hline \multirow[t]{4}{*}{ NSF-DOE-NCAR } & CESM1-BGC & 1 \\
\hline & CESM1-CAM5 & 3 \\
\hline & CESM1-FASTCHEM & 3 \\
\hline & CESM1-WACCM & 4 \\
\hline $\begin{array}{l}\text { Total number of } \\
\text { models/members }\end{array}$ & 48 & 158 \\
\hline
\end{tabular}

